\title{
Identification of the Factors, Barriers, and Motivations that Influence the Construction and Demolishing Waste Generation and Management
}

\author{
Vidyasekar, Selvan
}

\begin{abstract}
Because of the fast urbanization around the globe, a huge quantity of waste is generated. Inadequate processing of these wastes results in severe environmental damage. To minimize waste, effective waste management is necessary for the construction industry. This research paper evaluates and categorizes these variables based on their attitude, critical success factors, obstacles, motivations and factors that affect building and demolition waste management procedures.
\end{abstract}

\section{INTRODUCTION}

Because of the fast urbanization taking place, the majority of waste is generated by the building industry (Robert $\mathrm{H}$. Crawford et al. 2017). These waste disposal results in environmental effects such as groundwater and soil contamination, land degradation, habitat destruction, and methane release. Building waste materials are a combination of dangerous and non-hazardous materials. Depositing this waste should be thoroughly handled. Otherwise, it will lead to a serious environmental issue. The production of building products that lead to the exploitation of natural resources requires a significant quantity of natural resources. At the same time, a considerable portion of building waste can still be used for the purpose of construction. The way to use such materials in other building locations is to reuse them. Using the $3 \mathrm{R}$ principle, normally efficient leadership was created (Beijia Huang 2018). This article analyzes the crisp obstacles, motivations, factors that influence efficient techniques of waste management and critical success factors. This study offers knowledge of waste management efficiency and prioritizes waste management variables as well.

Previous statudies stated that the major contributor of the environmental degradation is construction sites. (Gangolells et al., 2014). For example, 40 percent of extracted virgin materials are utilized by the sector, while 10-35 percent of the waste contained in disposal locations is generated (Solis-Guzman et al., 2009; Periathamby, 2008). Literature reports very few research on the reuse and recycling of building waste in under-as well as middle-income nations and fewer surveys on variables affecting reduction practices execution. In low and middle income countries the reduced knowledge of the WM significantly reduced the effectiveness of waste management practices (Yuan and Shen, 2011).Few researchers from under-and middle-income nations who

researched the concrete reusing methods, wood wastes and mortar construction ceramics. Others reported recycling of

Revised Version Manuscript Received on 10 September, 2019.

Vidyasekar, Prist University, Chennai, Tamil Nadu, India.

Selvan, Prist University, Chennai, Tamil Nadu, India building waste, but mainly concrete aggregates (Letelier et al., 2017; Puthussery et al., 2017; Shahidan et al., 2017).

\section{METHODS TO ANALYSE BARRIERS OF WASTE MANAGEMENT}

By reviewing previous literature, (Amirreza Mahpour, 2018) identified 22 barriers. These barriers were prioritized with the assistance of Fuzzy TOPSIS. To promote C\&D management to a circular economy, this is useful. Based on their functional significance, multi-criteria decision-making methods are used to prioritize these barriers. Fuzzy TOPSIS is a technique of prioritizing preferences in this region. This technique includes fields for the prioritization of barriers in behavioural, technical and legal aspects. Barriers are recognized in waste management techniques to adapt to the circular economy. Through multiple works of literature, 22 barriers have been recognized. Barriers are weighed based on the waste management model's importance. The Fuzzy TOPSIS technique includes seven measures to prioritize and weigh C\&DWM's obstacles. Prioritization and barrier weighing based on fuzzy TOPSIS is used to formulate the structure for a waste management technique of a circular economy.

\subsection{Barriers And Motivations For Efficient Construction} Waste Management

The major barriers and motivations reported in the literature for the reduction of construction waste are classified into six aspects: Economic, Institutional, Ecological, socio-cultural, technical and legal (Guerrero et al., 2013). Figure 1 shows the value of four domains of concurrent consideration. Table 2 and 3 Shows the barriers and motivation for reducing construction waste using various aspects. 


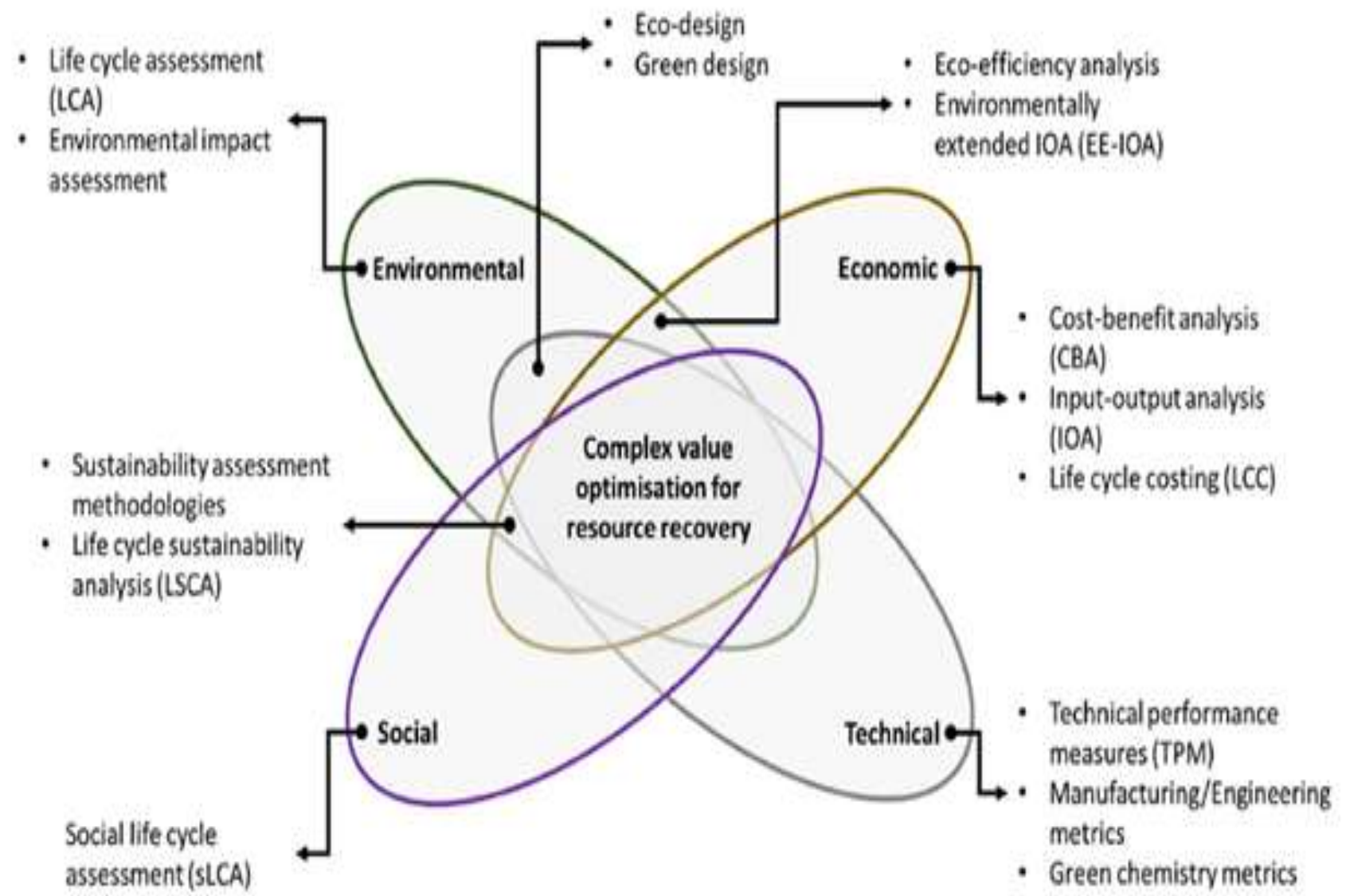

Figure 1: Environmental, Economic, Social and Technical of Concurrent Consideration (Source: Eleni Iacovidou et al., 2017)

\subsection{Analysis Of Waste Management Practices Through} Survey

In large construction sites, the analysis of waste management was conducted through surveys. Rate of economic development and gross productivity of WM was improved by selected provinces of construction site (National Economic and Social Development Board 2006). The targeted participant's construction project stakeholders. That is, they benefit from construction activities, or else they have been affected. The group of participants included project participants (e.g. owner of the site, directors, developers, technicians, supervisors, labours, Operators of waste disposal and recycling, etc.), Governent officials (e.g. in the Environment \& Construction Works Department) and neighbouring community members (e.g. individuals living/working close building locations). Table 1 shows details of the respondents. Large groups of participants were workers at construction sites (41\%), inhabitants (31\%) and GO's (24\%). The survey is not conducted based on the gender biases because the construction sector is male dominant sector and the percentages of female involved in construction research is about $25 \%$ to $44 \%$. This proportion is common in all construction sector. Moreover, descriptive statistics attained from the survey indicated that respondents have different opinions or similar opinions on specific problem. Figure 2 shows the graphical representation of the survey status.
Table 1: Survey status of respondents

\begin{tabular}{|c|c|c|c|c|c|c|}
\hline \multirow[b]{3}{*}{ Participation vith construction projacts } & \multicolumn{6}{|c|}{ Resposdents } \\
\hline & \multicolumn{2}{|c|}{ Male } & \multicolumn{2}{|c|}{ Female } & \multicolumn{2}{|c|}{ Orerall } \\
\hline & Count & 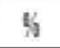 & Courst & $\%$ & Count: & y \\
\hline Owner & 2 & 100 & 0 & 0 & 2 & 0.5 \\
\hline Enginer & 32 & 94.1 & 2 & 59 & 34 & 8.9 \\
\hline Manager & 12 & 85.7 & 2 & 14.3 & 14 & 3.6 \\
\hline Worker & 20 & 54,1 & 17 & 45.9 & 37 & 9.5 \\
\hline Construtivn sector Government officials & 26 & 87 & 5 & 13 & 30 & 8.2 \\
\hline $\begin{array}{l}\text { Health \& environment sector Govenment } \\
\text { officials }\end{array}$ & 20 & 58 & 14 & 41 & 35 & 9.3 \\
\hline Supervizorforeman & 56 & 96.6 & 2 & 3.4 & 58 & 15.1 \\
\hline Neythbouring residents & 64 & 54 & 54 & 45 & 119 & 31.2 \\
\hline Goremment officials from other departments & 15 & 61 & 10.1 & 38 & 25 & 6.7 \\
\hline Recrycling company & 1 & 50 & 1 & 50 & 2 & 0.5 \\
\hline Others & 12 & 54 & 10.5 & 45 & 23 & 62 \\
\hline Total & 265 & 69 & 119 & 31 & 384 & 100 \\
\hline
\end{tabular}

Published By: 


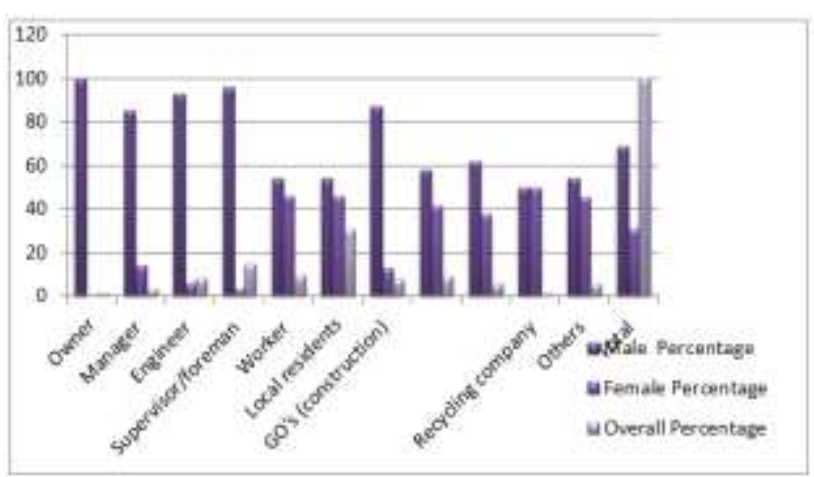

Figure 2: Graphical representation of survey status

\subsection{Optimizing Material Procurement For Waste Minimization}

Saheed O. Ajayi et al. (2017) investigated the wastes generated during the construction period, and he categorized waste generation areas into five groups they are design factors, Operations strategies, Material managing, construction managing process and external factors. Procurement strategies were taken into consideration to analyze the WM. The author has done the qualitative and quantitative data analysis followed by the analysis of the reasons behind the waste generation during the procurement process. From the findings, the author suggested that concentrating on four major areas were used to reduce the waste generated during construction.

\subsection{Factors Influences Waste Management}

(Hongping Yuan, 2013) investigated 30 key indicators which influenced the waste management practices and formed the framework which enhanced the effectiveness of waste management. This analysis categorizes the key factors into four major clusters, such as Construction and Demolition waste production, environmental, social, and economical performance. Based on these factors, a framework is developed to enhance the performance of present C\&D WM techniques. (Jongsung Won and Jack C.P. Cheng, 2017) determined the potential factors which influence waste management through BIM (Building Information Modelling). The factors were analyzed based on waste management and minimization hierarchy. BIM model has categorized Waste management practices into four major phases, such as planning, design, construction, and demolition. Each phase is related to BIM steps, and the correlation between each step is visualized using links, and the limitations of each step are noted for future use. Totally 23 limitations were identified from the BIM model, and these limitations were categorized into three issues such as process-related, technology-related, and policy-related issues.

Table 2: Barriers to reducing construction waste

\begin{tabular}{|c|c|}
\hline Aspect & Barrier \\
\hline \multirow{9}{*}{ Economic } & Contractors lacking financial penalization techniques for waste management \\
\hline & $\begin{array}{l}\text { Refusal to manage construction waste owing to high competition resulting from higher project } \\
\text { costs }\end{array}$ \\
\hline & Absence of well-developed market for waste recycling \\
\hline & Uneven distribution of waste reduction benefits, offering operators with a little incentive. \\
\hline & $\begin{array}{l}\text { The opinion that waste management operations are not economical, well-organized, practically } \\
\text { applicable with main construction operations. }\end{array}$ \\
\hline & $\begin{array}{l}\text { Refusal to separate materials with low economic value or difficult to reuse for recycling and } \\
\text { reuse }\end{array}$ \\
\hline & $\begin{array}{l}\text { The first importance is given to the financial profit not concerning the environmental } \\
\text { degradation problems }\end{array}$ \\
\hline & The cost of construction does not replicate the environmental cost \\
\hline & Focus only on asset costs not long term \\
\hline \multirow{10}{*}{ Institutional } & Management lack of engagement and support for waste issues \\
\hline & Absence of coordination between divisions \\
\hline & Lack of inclusion of skills and experience of operators in the WM process \\
\hline & Inadequate planning time for waste reduction techniques \\
\hline & Inconsistencies between different government agencies \\
\hline & Attention during planning and design phase of the construction is minimum \\
\hline & Unavailable WM methods \\
\hline & Waste management standards of the industry is not upto the standardized level \\
\hline & Individual allocation of WM duties are not properly defined \\
\hline & Customers are not involved in the earlier stages of construction such as design and planning. \\
\hline \multirow{6}{*}{ Ecological } & Knowledge about sustainable building methods is less \\
\hline & Inadequate professional training \\
\hline & University level construction site eduction is not upto the standard \\
\hline & Lack of environmental awareness by industry, policymakers and customers \\
\hline & Lack of training for construction employees on waste management problems \\
\hline & Government and private sector attention to housing deficits as opposed to environmental issues \\
\hline
\end{tabular}




\section{IDENTIFICATION OF THE FACTORS, BARRIERS, AND MOTIVATIONS THAT INFLUENCE THE CONSTRUCTION AND DEMOLISHING WASTE GENERATION AND MANAGEMENT}

\begin{tabular}{l|l}
\hline \multirow{4}{*}{ Technical } & Restricted Space significantly affect the efficiency of waste management \\
\cline { 2 - 2 } & Insufficient information on implementation methods of eco-technologies \\
\cline { 2 - 2 } & Poor skills in on-site building practices \\
\hline \multirow{4}{*}{ Socio-cultural } & Traditional construction culture and behaviour \\
\cline { 2 - 2 } & Poor gender recognition in construction site \\
\cline { 2 - 2 } & Low Force difficulties in training \\
\cline { 2 - 2 } & A belief that attempts to reduce waste will never be enough to eliminate waste \\
\hline \multirow{4}{*}{ Legal/policy } & \\
\cline { 2 - 2 } & Lack of enforcement of policies and plans for building and waste management \\
\cline { 2 - 2 } & Existing guidelines are challenging to activate the WM techniques in construction sites \\
\cline { 2 - 2 } & Lack of data available on environmental standards requirements \\
\cline { 2 - 2 } & Deficiency of environmental regulations \\
\hline
\end{tabular}

Table 3: Motivations for reducing construction waste

\begin{tabular}{|c|c|}
\hline \multirow{5}{*}{ Economic } & Awareness of cost reduction due to material loss reduction and raw material savings \\
\hline & Disposal cost is high in sites \\
\hline & Additional benefits resulting from the resale of by-products \\
\hline & Reduction of environmental and insurance related legal expenses (fines, compensation) \\
\hline & Energy Saving (electricity, fossil fuels) \\
\hline \multirow{4}{*}{ Institutional } & Company Image promotion \\
\hline & Following what the competitors have done \\
\hline & Organisations WM culture \\
\hline & Improve market share/competition \\
\hline Ecological & Environmental awareness of the industry \\
\hline \multirow{7}{*}{ Technical } & Purchase of disposal materials and machines for waste minimization \\
\hline & Waste management site space \\
\hline & Low waste WM techniques \\
\hline & Assistance or information from suppliers \\
\hline & Improving workers' skills \\
\hline & Recycled materials service experience \\
\hline & Development of recycled materials specifications and guidelines \\
\hline \multirow{2}{*}{ Socio-cultural } & Sustainable building demand by the clients \\
\hline & Attitudes of major practitioners \\
\hline \multirow{5}{*}{ Legal/policy } & The legal framework in place \\
\hline & Specific rules for using recycled material \\
\hline & Government environmental enforcement \\
\hline & Government environmental regulation \\
\hline & Government recycling mandates \\
\hline
\end{tabular}

\subsection{Waste Generation Factors}

(Roseline Ikau et al.,2013) investigated the waste generation factors of construction sites. This quantitative analysis was performed through direct interviews and the mail feedbacks from the respondents. The waste generation causes are categorized into four areas, such as Design, Procurement, Materials Handling, and Construction Causes. Feedbacks were collected from the respondents based on the classification of waste sources. From the analysis, the author found the major reasons for waste generation such as Lack of knowledge, Purchasing errors.

\subsection{Critical Success Factors Of Waste Management}

(Weisheng Lu a and Hongping Yuan, 2010) identified the CSF (Critical Success Factors) for managing wastes in construction sites. Regulations of waste management, System followed in Waste management (WMS), knowledge of C\&D WM, Low waste generating constrction methods, minimization of design changes, Waste management
Research \& Developement, and Professional training are the CSFs of handling waste management. (Amirreza Mahpour, 2018) analyzed the barriers of waste management and discussed the prioritization of barriers based on Fuzzy TOPSIS, which significantly enhanced the Waste management techniques. (Saheed O. Ajayi et al., 2017) analysed the reasons behind the waste generation in construction sites while material procurement and discussed the concentrate on four major areas such as Purchasing methods, suppliers commitment towards the waste management, delivery management and procurement which enhances the waste management methods. (Hongping Yuan, 2013) analyzed the key indicators which influence the waste management and made a classification on C\&D waste generation environmental performance social performance, and economic performance and discussed the framework is

Published By:

Blue Eyes Intelligence Engineering

\& Sciences Publication 
developed based on the key factors. (Jongsung Won and Jack C.P. Cheng, 2017) made a study on the Potential factors which influences waste management through BIM (Building Information Modeling) and discussed the limitations of each phase is analyzed and rectified using the suggestions taken in each limitation. (Roseline Ikau et al., 2013) studied the waste generation factors of construction sites and discussed the reasons behind the waste generation is listed as Lack of knowledge, Wrong material purchase, Improper storage . To enhance the waste management technique concentration on factors mentioned above should be analyzed. (Weisheng and Hongping Yuan, 2010) discussed limitations in CSFs and stated that it should be identified and rectified using various techniques and analyzed the CSF of Waste Management System

\section{RESULTS AND DISCUSSION}

Waste management is the process of handling the wastes in the construction sites. Barriers of waste management, Sources of waste generation, key indicators of waste management, factors influence waste management, and Critical success factors are analyzed in this research for enhancing the waste management techniques. Waste generation is the next major area which strongly influences the waste management system. Data were collected and quantitatively analyzed through field observations and surveys. The research shows that construction and demolition waste management is usually considered a significant rising issue. If there is no agreed situation of using the waste management scheme budget of a project adequately, the waste management efforts cannot be actively exercised. Commitment of supplier towards Waste management, purchase management, delivery management and procurement are the major clusters related to the sources of waste. Key indicators of the waste management system were identified to enhance and modify the framework for waste management. Finally, in this paper, research was conducted for the CSFs of waste management system. Identification of barriers, factors which influences waste management in this paper will be useful for future studies.

\section{REFERENCES}

1. Robert H. Crawford, Deepika Mathur, Rolf Gerritsen, Barriers to Improving the Environmental Performance of Construction Waste Management in Remote Communities, Procedia Engineering, Volume 196, 2017, Pages 830-837.

2. Beijia Huang, Xiangyu Wang, Harnwei Kua, Yong Geng, Raimund Bleischwitz, Jingzheng Ren, Construction and demolition waste management in China through the $3 \mathrm{R}$ principle, Resources, Conservation and Recycling, Volume 129, 2018 Pages 36-44.

3. Amirreza Mahpour, Prioritizing barriers to adopt circular economy in construction and demolition waste management, Resources, Conservation and Recycling, Volume 134, 2018, Pages 216-227.

4. Saheed O. Ajayi, Lukumon O. Oyedele, Muhammad Bilal, Olugbenga O. Akinade, Hafiz A. Alaka, Hakeem A. Owolabi, Critical management practices influencing on-site waste minimization in construction projects, Waste Management, Volume 59, 2017, Pages 330 -339.

5. Hongping Yuan, A SWOT analysis of successful construction waste management, Journal of Cleaner
Production, Volume 39, 2013, Pages 1-8.

6. Jongsung Won, Jack C.P. Cheng, Identifying potential opportunities of building information modelling for construction and demolition waste management and minimization, Automation in Construction, Volume 79, 2017, Pages 3-18.

7. Roseline Ikau, Corina Joseph, Rudy Tawie, Factors Influencing Waste Generation in the Construction Industry in Malaysia, Procedia - Social and Behavioral Sciences, Volume 234, 2016, Pages 11-18.

8. Weisheng Lu, Hongping Yuan, Exploring critical success factors for waste management in construction projects of China, Resources, Conservation and Recycling, Volume 55, Issue 2, 2010, Pages 201-208.

9. Gangolells, M.; Casals, M.; Forcada, N.; Macarulla, M. Analysis of the implementation of effective waste management practices in construction projects and sites. Resour. Conserv. Recycle. 2014, 93, 99-111.

10. Solís-Guzmán, J.; Marrero, M.; Montes-Delgado, M.V.; Ramírez-de-Arellano, A. A Spanish model for quantification and management of construction. Waste Manag. 2009, 29, 2542-2548.

11. Periathamby, A. Challenges in the sustainable management of construction and demolition waste. Waste Manag. Res. 2008, 26, 491-492.

12. Letelier, V.; Tarela, E.; Muñoz, P.; Moriconic, G. Combined effects of recycled hydrated cement and recycled aggregates on the mechanical properties of concrete. Constr. Build. Mater. 2017, 132, 365-375.

13. Puthussery, J.V.; Kumar, R.; Garg, A. Evaluation of recycled concrete aggregates for their suitability in construction activities: An experimental study. Waste Manag. 2017, 60, 270-276.

14. Shahidan, S.; Azmi, M.A.M.; Kupusamy, K.; Zuki, S.S.M.; Ali, N. Utilizing Construction and Demolition (C\&D) Waste as Recycled Aggregates (RA) in Concrete. Procedia Eng. 2017, 174, 1028-1035.

15. Guerrero, L.A.; Maas, G.; Hogland, W. Solid waste management challenges for cities in developing countries. J. Waste Manag. 2013, 33, 220-232.

16. Yuan, H.; Shen, L.; Wang, J. Major obstacles to improving the performance of waste management in China's construction industry. Facilities 2011, 29, 224-242. 24.

17. Manowong, E. Investigating factors influencing construction waste management efforts in developing countries: An experience from Thailand. Waste Manag. Res. 2012, 30, 56-71.

18. Thomas, H.R. 2000 Peurifoy Lecture: Construction practices in developing countries. J. Constr. Eng. Manag. 2002, 128, 1-7.

19. Eleni Iacovidou, Costas A. Velis, Phil Purnell, Oliver Zwirner, Andrew Brown, John Hahladakis, Joel Millward-Hopkins, Paul T. Williams, Metrics for optimising the multi-dimensional value of resources recovered from waste in a circular economy: A critical review, Journal of Cleaner Production, Volume 166, 2017, Pages 910-938. 